\title{
Os desafios da escrita do trabalho de conclusão de curso de pedagogia em uma universidade maranhense
}

\author{
Rhaiza Ludimila Gomes Vieira ${ }^{1}$ \\ Jónata Ferreira Moura ${ }^{2}$
}

\section{Resumo}

Este artigo trata dos desafios da produção do TCC de Pedagogia entre 2013 e 2016 em uma universidade maranhense. Realizou-se uma pesquisa documental objetivando analisar os desafios do letramento acadêmico revelados nos TCC de alunos e avaliar o uso das normas da ABNT na escrita e apresentação do texto, do resumo, das citações e das referências. Analisou-se uma amostra de 56 TCC. Os resultados mostraram que estes foram estruturados nas normas da ABNT e que há algumas dificuldades na escrita do título, no uso de citações e produção do resumo. As dificuldades no uso das relações dialógicas e a sustentação da argumentação fundamentada nos enunciados teóricos foram os elementos com maior destaque. Os discentes necessitam aprender o letramento acadêmico para inserirem-se no espaço universitário.

Palavras-chave: Letramento Acadêmico; Gênero Discursivo; Curso de Pedagogia; TCC.

\section{The challenges of the writing work for completing the pedagogy course of a maranhens university}

\section{Abstract}

This article discusses the challenges of producing the Pedagogy TCC between 2013 and 2016 at a university in Maranhão. To this end, a documentary research was carried out with a qualitative approach aiming to analyze the challenges of academic literacy revealed in the students' TCC and to evaluate the use of ABNT standards in the writing and presentation of the text, abstract, citations and references. A sample of 56 TCC was analyzed. The results showed that the TCC were structured according to ABNT rules and that there are some difficulties in writing the title, in using citations and in producing the abstract. The difficulties in the use of dialogical relations and the support of the argument based on the theoretical statements were the elements with greater emphasis in the CBT. Students need to learn academic literacy to enter the university space.

Keywords: Academic Literacy; Discourse Genre; Pedagogy Course; TCC.

\section{Considerações iniciais}

O desenvolvimento da escrita universitária faz parte de um processo, nada simples, chamado letramento acadêmico. Este é a capacidade de os alunos universitários alcançarem o domínio do uso de diversos gêneros discursivos dentro da academia, além das exigências de que

\footnotetext{
${ }^{1}$ Universidade Estadual da Região Tocantins do Maranhão (UEMASUL) e Faculdade Vale do Aço (FAVALE). Imperatriz. rhaizaludimilav@gamil.com.

2 Universidade Federal do Maranhão, Imperatriz. jf.moura@ufma.br.
} 
saibam ler, compreender e produzir gêneros escritos, como relatórios de pesquisa, resumos, resenhas, Trabalho de Conclusão do Curso (TCC), bem como gêneros verbais, como seminários, arguições, exposição oral (MORETTO, 2014).

Neste artigo, apresentamos uma investigação do tipo qualitativa com os seguintes objetivos: analisar os desafios do letramento acadêmico revelados pelos TCC dos alunos do curso de Pedagogia do período de 2013 a 2017 e avaliar o uso das normas da ABNT na escrita e apresentação do TCC, do resumo, das citações e das referências. Para isso, realizamos uma análise documental com uma amostra de 56 TCC.

Apresentamos, a seguir, a metodologia da pesquisa. Depois, discutimos algumas ideias sobre letramento acadêmico. Exibimos também a análise da pesquisa. Por fim, expomos nossas considerações finais.

\section{Metodologia da pesquisa}

Esta é uma pesquisa qualitativa do tipo documental. Ela foi desenvolvida por meio da análise seletiva de TCC de Pedagogia do período de 2013 a 2016 de uma universidade do Maranhão.

Segundo Helder (2006, p.2), "a técnica documental vale-se de documentos originais, que ainda não receberam tratamento analítico por nenhum autor [...], é uma das técnicas decisivas para a pesquisa em ciências sociais e humanas". Por esse prisma, podemos dizer que a pesquisa documental é aquela em que os dados obtidos são estritamente provenientes de documentos, como é o caso dos TCC que compõem o corpus desta investigação.

Flick (2009) ressalta que, em um estudo documental, o pesquisador deve entender os documentos como "meios de comunicação", pois foram elaborados com algum propósito, sendo inclusive destinados para que alguém tivesse acesso a eles. Os TCC analisados se enquadram nesse perfil.

Neste artigo, realizamos duas fases de análise. Na primeira, elencamos quais TCC possuíam toda a estrutura seguindo as normas da ABNT para a escrita e a apresentação, o resumo, as citações e as referências, observando o corte temporal de 2013, ano da última reformulação do Projeto Pedagógico do Curso, a 2016, penúltimo ano da existência da 
universidade. Buscamos os TCC na biblioteca da universidade, totalizando 56 amostras disponíveis.

Lendo cada um dos resumos, fizemos uma pré-análise para identificar os principais elementos que os trabalhos contêm e suas temáticas. Após essa etapa, utilizamos todos os 56 trabalhos, pois mantinham em sua estrutura todos os itens de um TCC no formato monográfico sugerido pela ABNT. A segunda etapa da análise foi a identificação de seus elementos textuais e o letramento acadêmico.

Não identificamos a autoria dos TCC analisados ao longo do texto. Fizemos essa opção para resguardar o anonimato dos autores dos trabalhos. Os TCC, assim, estão nomeados com o número que representa a ordem em que foram analisados (TCC1, TCC2 etc.).

Partindo do pressuposto de que o TCC é um gênero discursivo acadêmico composto por uma estrutura padronizada, ressaltamos a necessidade de analisá-la, visto que as subdivisões podem se diferenciar uma das outras no que diz respeito ao contexto de produção do discurso e na conjuntura sócio-histórica, linguageira e física. Antes, faz-se necessário discutir algumas ideias sobre letramento acadêmico.

\section{Algumas ideias sobre letramento acadêmico}

As discussões sobre letramento acadêmico vêm sendo sustentadas pelo fazer pensar dos Novos Estudos do Letramento (LEA; STREET, 2006, 2014; STREET, 2010). Segundo Gee (1999, 2000, 2001), o letramento acadêmico implica formas de estar no mundo, representa um conjunto de convenções que determinam os modos de pensar, comportar-se, falar, ler, escrever, interagir, valorizar e acreditar. Com isso, conceituá-lo vai além da decodificação ou codificação da linguagem, por isso não é uma tarefa das mais simples.

O conceito de letramento é bastante abrangente, tendo em vista que existe uma diversidade deles. E podemos afirmar que, devido às mudanças sociais ocorridas em nossa sociedade e às novas exigências sobre os conhecimentos da leitura e da escrita, esse termo vem sofrendo ressignificações.

Alguns autores brasileiros e estrangeiros abordam o letramento em dois modelos: o autônomo e o ideológico. Destacam também dois componentes básicos dos fenômenos de 
letramento, os ditos eventos de letramento e as práticas de letramento.

No 'modelo autônomo', a tendência é enfocar a dimensão técnica e individual do letramento e considerar as atividades de leitura e escrita como neutras e universais, independentes dos determinantes culturais e das estruturas de poder que as configuram, no contexto social. [...] o 'modelo ideológico' enfoca a dimensão social do letramento, apresentando diferentes versões em que o conceito de letramento se fundamenta [...] (MORTATTI, 2004, p.100-101).

O letramento é pensado como atividade única e singular; e a prática letrada, como universal, invariável e repetitiva, já que é a mesma em qualquer situação comunicativa em que figurar. Portanto, na abordagem autônoma, defende-se que a compreensão do código linguístico é suficiente para entendê-lo como tal (SILVA; ARAÚJO, 2012).

Na abordagem ideológica, leitura e escrita são consideradas atividades de caráter social, que podem variar no tempo e no espaço, dependendo do tipo de sociedade, dos projetos políticos existentes, do meio cultural e social em que ela se insere. Partindo desse pressuposto, o modelo ideológico "defende que a leitura e a escrita sejam consideradas interligadas à ideologia e ao contexto sócio-histórico em que aparecem" (SILVA; ARAÚJO, 2012, p.682).

Nesse enfoque, os eventos e práticas de letramento exercidos no âmbito educativo se tornam objetos de ensino e aprendizagem que estruturam uma organização sistemática e metódica. Isso ocorre mediante seleção e estabelecimento de acordo com critérios pedagógicos de conteúdos e atividades a serem desenvolvidos e avaliados, objetivando alcançar a aprendizagem dos alunos (MORTATTI, 2004).

Os estudantes constroem seus saberes científicos nos eventos de letramento acadêmico. E ainda, segundo Gee (1999, 2000), edificam um conjunto de posicionamentos ideológicos, significados culturais e estruturas de poder que, em conjunto, constituem o modo cultural de usar os textos. Ou seja, esses eventos são responsáveis por integrarem a construção do letramento acadêmico, gerando as condições para a aquisição dos padrões do discurso dominante da instituição.

Nos eventos de letramento, o enunciado, nos dizeres de Bakhtin (2010), aparece de forma oral ou escrita. Ele reflete as condições singulares e as finalidades de cada referido campo, pois, além de tratar de sua temática e do estilo da linguagem, aborda a construção 
composicional. Essas três características estão interligadas no todo do enunciado. Esse todo do enunciado, por sua vez, pode ser chamado de gênero do discurso, o qual pode ser primário ou secundário. O letramento acadêmico é um gênero secundário do discurso, pois suas características estão externas ao sujeito, e este precisa ir ao encontro dele. Com isso, Bakhtin (2010, p. 284) recomenda: "é preciso dominar bem os gêneros para empregá-los livremente."

Para dominar bem os gêneros secundários discursivos, os Novos Estudos do Letramento sustentam a ideia de três abordagens sobre o letramento acadêmico. A primeira é a das habilidades de estudo, que "[...] concentra-se nos aspectos da superfície da forma da língua e pressupõe que estudantes podem transferir seu conhecimento de escrita e letramento de um contexto para outro, sem quaisquer problemas" (LEA; STREET, 2014, p.479). A segunda é a da socialização acadêmica, em que "estudantes adquirem modos de falar, escrever, pensar e interagir em práticas de letramento que caracterizavam membros de comunidade disciplinar ou temática" (LEA; STREET, 2014, p.479); é muito usada na maneira oral. Por último, a abordagem dos letramentos acadêmicos tem

relação com a produção de sentido, identidade, poder e autoridade; coloca em primeiro plano a natureza institucional daquilo que conta como conhecimento em qualquer contexto acadêmico específico. Assemelha-se, em muitos aspectos, ao modelo de socialização acadêmica, exceto pelo fato de considerar os processos envolvidos na aquisição de usos adequados e eficazes de letramento como mais complexos, dinâmicos, matizados, situados, o que abrange tanto questões epistemológicas quanto processos sociais incluindo: relações de poder entre pessoas, instituições e identidades sociais (LEA; STREET, 2014, p.479).

Por esse prisma, compreendemos o letramento acadêmico como uma prática social situada. Ele envolve estratégias discursivas relacionadas com capacidades para usar códigos utilizados nos contextos acadêmicos, para ler e escrever textos nos gêneros dessa esfera, de modo que os conhecimentos adquiridos na academia sejam vivenciados na vida sociocultural, experimentando situações novas pautadas no âmbito da universidade (KLEIMAN, 2008).

Ou ainda, o letramento acadêmico seria a capacidade de os alunos universitários dominarem diversos gêneros discursivos exigidos dentro da academia. Assim, pressupõe que os estudantes saibam ler, compreender e produzir diversos gêneros escritos e orais para que se 
tornem futuros pesquisadores e autores de produções científicas.

A problemática, entretanto, consiste no fato de que esses gêneros, assim como o contato com o universo da esfera acadêmica, são, na maioria das vezes, uma nova experiência para muitos alunos que, pela primeira vez, estão inseridos no ensino superior. Com isso, no entendimento de Marquesin, Benevides e Baptista (2011), ensinar a escrever um texto acadêmico torna-se um caminho recheado de problemas e impasses, pois o docente, muitas vezes, acredita que receberá o aluno pronto; contudo, essa não é a realidade dos espaços universitários brasileiros.

Essa realidade teima em perdurar e, em muitos casos, estender-se no espaço universitário. Com isso, os acadêmicos têm constantes inquietações, em especial quanto à escrita do TCC, não só no que se refere à escolha do tema, mas, principalmente, no que é relativo à lógica composicional desse gênero secundário do discurso. A seguir, analisamos os desafios na escrita do TCC de Pedagogia em uma universidade maranhense.

\section{Desafios da escrita do trabalho de conclusão de curso de pedagogia em uma universidade maranhense}

O TCC tem a intenção de despertar e estimular nos acadêmicos a produção científica. Nessa perspectiva, a construção de um TCC não é tarefa simples, ainda mais quando é o primeiro contato do acadêmico com a escrita específica de um tema de pesquisa. Ele pode ser um trabalho, comumente, dissertativo; contudo, pode-se utilizar dos aspectos da narração para sua constituição.

Segundo Moretto (2016, p.109), “os escritos produzidos pelos estudantes se configuram como textos bastante complexos, à medida que este se configura como um trabalho de cunho intelectual em que o aluno deve expressar os conhecimentos adquiridos durante sua trajetória acadêmica".

O TCC é um texto impresso com seções, como: capa, folha de rosto, folha de aprovação, dedicatória, agradecimentos, resumo, sumário, introdução, fundamentação teórica, metodologia, discussão e análise dos dados, conclusão e referências bibliográficas. É manifestado por uma linguagem formal: 
$O$ fato de se configurarem em textos que exigem do educando um amadurecimento intelectual e teórico, o TCC se manifesta por meio de uma linguagem formal. Quanto ao contexto sócio-histórico, é um gênero que exige do produtor um conhecimento amplo sobre um determinado tema (MORETTO, 2016, p.109).

Pelas características acima, podemos dizer que, para uma boa escrita do TCC, não há uma receita pronta. Contudo, o docente pode orientar o discente, apresentando a ele as regras metodológicas que norteiam a escrita acadêmica, guiando-o no uso correto das referidas normas. Sabendo que essa atividade é complexa, Riolfi e Andrade (2009) dizem que orientar um trabalho e redigir um texto exige um compromisso compartilhado entre aquele que se dispõe a escrever - que precisa antever a possibilidade de sempre reler, rever e reescrever - e aquele que orienta - que necessita checar o rigor teórico-metodológico do que está escrito.

Uma das primeiras dificuldades ao produzir o TCC é dar um título, afinal de contas este é o primeiro enunciado do texto. Ele é o cartão de visita de qualquer trabalho científico. Para muitos pesquisadores, o melhor momento para formulá-lo é ao final da produção do texto. Por qual motivo? Para Imbelloni (2012, p.140), esse seria um caminho aceitável, porque

o título deve ser um 'resumo bem compactado' de cada trabalho científico. Se bem escrito, pode ser o principal motivo para que alguém leia o que está sendo oferecido. O título tem uma função muito importante porque esclarece o assunto a ser tratado no texto, chama a atenção do leitor e instiga a leitura, além de criar um suporte ao texto.

Considerando as análises feitas nos TCC, podemos visualizar algumas recomendações de Imbelloni (2012) em alguns trabalhos dos alunos do curso de Pedagogia de 2013 a 2016, expostos no Quadro 1:

Quadro 1 - Títulos de TCC

TCC9: A orientação sexual no ambiente escolar: a desmistificação de tabus por meio de um projeto de mediação pedagógica

TCC25: A perspectiva das mães sobre a participação familiar no cotidiano escolar

TCC32: Jogos e brincadeiras como recurso pedagógico no desenvolvimento das crianças na educação infantil

Fonte: Arquivo da pesquisa. 
Esses títulos são constituídos por frase nominais, não apresentando verbos. Eles manifestam o assunto principal do TCC como um todo e são registrados em letra maiúsculas, alinhamento centralizado e negrito. Contudo, como a produção científica é complexa e problemas podem existir também na composição do título, encontramos outros TCC com equívocos na escrita dele, como: contexto determinístico; registro prolixo; e uso das palavras estudo, investigação, identificação e caracterização. Como exemplo, apresentamos no Quadro 2 alguns que podem ser representativos do conjunto de muitos com as mesmas complicações:

Quadro 2 - Títulos de TCC

TCC2: Tratamento da informação na educação básica: um estudo comparativo entre duas escolas da rede municipal de ensino de Imperatriz/MA

TCC45: A orientação sexual na educação infantil é o meio de prevenção à violência sexual: identificando concepções antidemocráticas

TCC22: A caracterização do desenvolvimento de crianças e jovens como uma investigação dos primeiros anos escolares

Fonte: Arquivo da pesquisa.

Nos três títulos acima, há o uso das palavras estudo, investigação e caracterização e do verbo identificando. Elas são muito comuns em textos científicos; todavia, é sempre bom evitálas, visto que quem se dedica a realizar uma pesquisa faz um estudo, investiga, pode caracterizar e até mesmo identificar algo. Então, a repetição do fazer científico no título deixa-o prolixo, pois essas ações estão implícitas na atividade do pesquisador.

No TCC45, o autor titula-o A orientação sexual na educação infantil é o meio de prevenção à violência sexual: identificando concepções antidemocráticas. Para nosso entendimento, o verbo ser é poluente, pode ser excluído e substituído pela conjunção como sem causar nenhum dano à compreensão de quem o lê. Além disso, o é resulta em um título determinístico, com indícios de um ativismo nada usual na escrita acadêmica, parecendo ser uma forte alegação de que o pensamento do autor não pode ser contestável. Então, é importante rever com bastante atenção o título antes da publicação do trabalho, pois "no mundo moderno as pessoas selecionam o que vão ler pelo título: se este as agradar, elas leem o resumo; e, se o resumo as estimular, lerão o trabalho completo" (IMBELLONI, 2012, p.140). 
Mendes (2010) também trata da relação entre título e resumo. Para o autor, esses dois elementos podem facilitar a vida dos leitores, que parecem ter um tempo cada vez mais curto. Pensando nisso, é prudente levar em consideração que, após o título, o resumo é o primeiro texto lido quando se busca informações em repositórios de instituições, em bancos de dados, em periódicos. Assim, se o texto não for de interesse e relevância, o leitor não estará convencido a ler o restante da obra.

Concordamos com os autores citados acima. Acreditamos que o resumo, se bem elaborado, permite ao leitor identificar rapidamente o teor do trabalho, conseguindo determinar se ele é de seu interesse e, portanto, se vale a pena lê-lo por completo.

A escrita do resumo deve descrever como a pesquisa aconteceu e ser impessoal. Além disso, para Henry-Silva, Soeiro e Camargo (2009, p.3), ele deve ser escrito "no passado simples, porque se refere a um trabalho já concluído." Os autores também recomendam: "nunca forneça informações ou conclusões que não são citadas no [TCC]. Referências de literatura não devem ser mencionadas no resumo (exceto em raras ocasiões)" (HENRY-SILVA; SOEIRO; CAMARGO, 2009, p.3).

Nos 56 resumos analisados, alguns equívocos no contexto produtivo e físico aparecem. Contudo, há uso acertado da norma ABNT/NBR 6028, de 2003, que trata da composição do resumo - tema, objetivos, problema, local da pesquisa, sujeitos da pesquisa, metodologia (análise dos dados/ instrumentos de coleta de dados), resultados, palavras-chaves - para um relatório de uma pesquisa. De acordo com esse documento, a extensão dessa seção deve variar de 150 a 500 palavras; e a primeira frase deve ser significativa, explicando o tema principal do TCC.

Ademais, Henry-Silva, Soeiro e Camargo (2009, p.4) advertem: “o resumo não deve conter referências bibliográficas, figuras, ou tabelas, sua linguagem deve ser familiar para o leitor. Além disso, no resumo deve-se omitir abreviações pouco conhecidas". Ainda há as indicações de Moretto (2016, p.112) sobre a ausência de implicações de quem escreve o texto, remetendo "o leitor a um momento anterior à enunciação real, o que dá ao texto um caráter de objetividade, imparcialidade e cientificidade". Como exemplo dos desafios desse tipo de escrita, apresentamos, no Quadro 3, o resumo do TCC30. 
Quadro 3 - Resumo

TCC30: Este trabalho de conclusão de curso discute as práticas de letramento no Ensino Fundamental analisando a experiência de uma professora do 1음 ano, baseando-se nas tarefas de classe propostas por ela, durante a pesquisa, a seus estudantes, e uma entrevista semiestruturada. Produzimos uma pesquisa empírica com abordagem qualitativa, tendo como problemática: Como acontecem as práticas de letramento de uma professora do 10 ano do Ensino Fundamental da rede municipal de Imperatriz? Para entendermos essa problemática baseamo-nos nos estudos de Magda Soares e Maria Mortatti. Na pesquisa, realizada numa escola pública da rede municipal de Imperatriz - MA com os alunos e a professora do 10 ano do Ensino Fundamental, utilizamos as tarefas propostas pela professora para produção dos dados da pesquisa. A análise se deu pelos eventos de letramento, considerando as tarefas que estavam inseridas no contexto das práticas sociais. Os resultados revelam que a prática pedagógica da professora, mesmo diante dos desafios de grande parte dos professores do 1 o ano do Ensino Fundamental, é reveladora de significados para seus alunos, uma vez que, por meio dos eventos de letramento percebemos que as crianças estão, com a ajuda da professora, atribuindo significação à leitura e à escrita; a pesquisa também foi fundamental para mostrar que é possível alfabetizar mediante o uso dos métodos de alfabetização e encarando o letramento como elemento indispensável no processo de alfabetização, inserindo práticas e eventos de letramento.

Palavras-chave: Alfabetização e Letramento. Eventos de Letramento. 1o Ano do Ensino Fundamental.

Fonte: Arquivo da pesquisa.

No resumo acima, temos verbos no presente. A dúvida pode aparecer caso o leitor não entenda o contexto em que foi escrito o resumo e ainda não acompanhe os demais tempos verbais, pois os verbos produzir (produzimos), realizar (realizamos), perceber (percebemos) e basear (baseamo-nos) podem ter essas mesmas conjugações no pretérito perfeito. Contudo, o texto carece de coerência verbal, o que é visto na conjugação do verbo revelar (revelam) no presente, dando o indício necessário de que os demais verbos também estão no presente, o que não é aconselhável. Retomamos aqui a importância do uso do pretérito perfeito para se referir a um trabalho já concluído, expondo um momento anterior à enunciação real e descrevendo como a investigação aconteceu, o que é o esperado em um resumo.

Os verbos conjugados na primeira pessoa do plural também não são recomendáveis, mesmo que a abordagem de estudo se filie à pesquisa do tipo qualitativa ${ }^{3}$ e/ou encarnada ${ }^{4}$. 0 uso desse tempo verbal, no resumo, descaracteriza sua objetividade, sua imparcialidade e sua

\footnotetext{
${ }^{3}$ É costume, nas pesquisas qualitativas, o uso da conjugação verbal na primeira pessoa do singular ou do plural, com o intuito de distanciamento com os princípios epistemológicos das pesquisas positivistas.

${ }^{4}$ Pesquisas que utilizam a conjugação verbal na primeira pessoa do singular e ainda possuem vertente nos estudos (auto)biográficos. Para maiores informações, ver Najmanovich (2001).
} 
cientificidade. Com isso, devemos seguir a recomendação dos autores já citados e da norma ABNT/NBR 6028, de 2003.

Também temos a menção de duas autoras que, supostamente, são os pilares da investigação, o que não é recomendável. Caso o pesquisador queira mencionar suas principais referências, a introdução é a seção apropriada para fazê-lo.

Em nosso entendimento, os recursos linguísticos utilizados pelos enunciadores, em todo o TCC, mas, em especial, no resumo, manifestam o papel que eles assumem na comunicação verbal, isto é, "o sujeito se posiciona de acordo com as representações que têm do contexto de produção, de seus interlocutores, do momento da produção" (MORETTO, 2016, p.112). Esse papel pode ser visto já no resumo dos trabalhos; e se a ideia é posicionar-se, não se pode deixar de lado a objetividade, a imparcialidade e a cientificidade na escrita do resumo.

Passamos agora para a primeira seção dos elementos textuais do TCC: a introdução. Ela é escrita, na maior parte das vezes, no tempo presente, pois isso representa a ideia de que se está constituindo o conhecimento para dar início ao trabalho. E, no entendimento de HenrySilva, Soeiro e Camargo (2009, p.4), tem como principal propósito

fornecer informações suficientes para que o leitor compreenda e avalie os resultados do estudo, sem ter a necessidade de consultar publicações anteriores sobre o assunto. Além disso, é necessário expor, de forma breve e clara, quais são os objetivos do trabalho e escolher as referências adequadas para informar sobre o tema abordado. $\mathrm{Na}$ introdução deve-se prender a atenção inicial do leitor, além de justificar o porquê da escolha do tema e qual a importância de estudá-lo.

Em nossa avaliação, identificamos em 50 TCC a presença das questões norteadoras, da explicação do tema a ser abordado, dos objetivos, dos aportes teóricos e da metodologia da investigação. Em 18 TCC, a introdução apresentou o contexto histórico da temática. Já em 6 TCC, percebemos a existência de algumas conclusões baseadas nos resultados da pesquisa.

A título de compreensão do leitor, segue, no Quadro 4, o excerto do TCC 56 que apresenta o tema do estudo: 
Quadro 4-Trecho de uma introdução

A educação inclusiva é um movimento que compreende a educação como um direito humano fundamental e a base para uma sociedade mais justa e solidária. É uma conquista que exige muito estudo, trabalho e dedicação de todos os envolvidos no processo educacional como: aluno surdo e ouvinte, família, professores, e todos os envolvidos no contexto escolar.

Fonte: Arquivo da pesquisa.

No Quadro 5, citamos o TCC 12, que justifica a escolha do tema:

Quadro 5 - Trecho de uma introdução

Destacamos que, a escolha do tema surgiu em dois momentos: primeiro em meio ao estudo da disciplina de Educação Especial, atualmente inclusa no currículo do curso de Pedagogia do [...], por meio da qual, percebemos a importância de conhecer as especificidades de alunos com Necessidades Educacionais Especiais, bem como compreender o papel do professor no atendimento a esses alunos. É importante ressaltarmos que sentimos a carência de um estágio exclusivamente voltado para essa área, que nos proporcionasse uma relação mais próxima com a educação inclusiva em nossa cidade.

O segundo momento foi durante a disciplina de Prática na Dimensão Docente, quando nos deparamos com a proposta de inclusão na realidade escolar. Durante esta disciplina verificamos que a necessidade de um estágio voltado para a educação inclusiva deveria ter sido suprida, pois, sentimos de perto, durante esse estágio curricular algumas dificuldades enfrentadas pelos professores e até mesmo em relação a nossa prática docente no atendimento aos alunos especiais. E assim entendemos a necessidade de pesquisar e compreender como estão sendo qualificados os educadores para atender a educação inclusiva.

Fonte: Arquivo da pesquisa.

E o Quadro 6 contém um trecho do TCC 27, que apresenta as principais bases teóricas em que a pesquisa se fundamenta, com uma breve discussão:

Quadro 6 - Trecho de uma introdução

O delineamento do presente estudo ocorre da seguinte forma: é amparado nos estudos bibliográficos e empírico, baseado em autores como, Alambert (2004), Novaes (1995), Louro (2010), Bauer (2001) entre outros. Sendo assim, temos uma breve discussão sobre a mulher professora no contexto brasileiro, no qual enfatizamos a influência do movimento feminista para a docência, base de superação das ideologias colocadas ao universo feminino, a fim de combater as determinações que recaíam sobre as mulheres advindas de séculos de exclusão.

Fonte: Arquivo da pesquisa.

Como assegura Severino (1996), o TCC é o trabalho científico que se propõe a abordar um tema único, dentro de um tratamento teórico e metodológico específico. Com isso, esperamos que, em sua introdução, o tema e o objeto de estudo, a teoria e o método estejam especificados, como vemos nos excertos acima. 
Observamos que é na introdução que os TCC apresentam a metodologia do estudo, com poucas discussões. Dois TCC contêm uma seção distinta para a metodologia. Os demais apresentam na introdução o tipo de pesquisa, os sujeitos da investigação, os instrumentos de produção de dados e a maneira como fazem a análise. Ao fazer isso nessa seção, os autores mostram que suas escolhas linguísticas funcionam, a todo o momento, como estratégias para a construção da argumentação, amparadas nos enunciados de suas referências, porque usam os enunciados de outros textos. Um exemplo disso está no Quadro 7:

Quadro 7-Trecho de uma introdução

TCC56: Quanto à abordagem da pesquisa, adotamos a qualitativa, que nos permitiu compreender e interpretar o fenômeno observado bem como identificar e descrever as concepções dos atores a quem se destina a pesquisa. Segundo Teixeira $(2008$, p.137) "na pesquisa qualitativa o pesquisador procura reduzir a distância entre a teoria e os dados, entre o contexto e a ação [...]". A pesquisa de campo foi assim delimitada às escolas da rede pública municipal de Imperatriz/Ma, sendo assim realizada nos meses de junho e julho de 2011. [...]

Quanto aos informantes, estes são os professores que concluíram a graduação de Pedagogia nos últimos cinco anos e que atendem a demanda de alunos com Necessidades Educacionais Especiais no ensino regular. Escolhemos esses sujeitos para realizar a pesquisa, tendo em vista que as disciplinas que correspondem à educação inclusiva entraram recentemente na estrutura curricular dos cursos de Pedagogia na cidade de Imperatriz/Ma. É importante salientar que as três professoras entrevistadas foram encontradas mediante a visita a 21 escolas situadas em vários bairros da cidade, tais como: Centro, Nova Imperatriz, Bacuri, Santa Inês, São José, Ouro Verde, Boca da Mata, Santa Rita, Vilinha e Juçara. Dentre as escolas pesquisadas encontramos cinco professoras que se ajustaram ao perfil de informantes da pesquisa, no entanto, apenas três aceitaram conceder entrevista.

Fonte: Arquivo da pesquisa.

Assim como os demais estudiosos que apresentamos anteriormente, Martins (2000) indica que uma boa introdução é aquela que não é uma repetição ou paráfrase do resumo. Ela precisa abordar os antecedentes do problema, as tendências, os pontos críticos, as preocupações, além de expor as justificativas e razões para a elaboração do trabalho, destacando a relevância do tema.

Além das regras acima, faz-se necessário que o escritor do TCC tenha em mente que seu trabalho pode ser lido por pessoas de outras áreas. Por isso, a introdução é a seção apropriada para definir alguns termos muito particulares da temática ou abreviações que pretende utilizar no decorrer do texto.

Ao finalizar a introdução, o autor do TCC deve se preocupar em apresentar o trabalho por inteiro para seus possíveis leitores. Recomendamos sintetizar cada capítulo em parágrafos curtos e 
escrevê-los ao final da introdução, como uma prévia para os leitores do que consta em cada seção.

Em grande parte dos TCC analisados, visualizamos essa indicação, como vemos no Quadro 8.

Quadro 8-Trecho de uma introdução

TCC39: Para melhor organizarmos a pesquisa, dividimos o presente TCC em capítulos, mostrando o andamento da pesquisa até sua fase final. No capítulo segundo abordo a cultura escolar, e as diferentes situações escolares e culturais que as crianças passaram, evidenciando que, por meio dessas culturas diversas, têm-se hoje as peculiaridades em educar, bem como desconstruir culturas edificadas por anos. Já no terceiro capítulo é abordado à vida escolar das crianças, suas dificuldades ao aprender matemática e língua portuguesa, mostrando suas fragilidades e determinações. 0 capítulo quatro refere-se à conclusão do trabalho, trazendo algumas considerações julgadas importantes para este trabalho.

Fonte: Arquivo da pesquisa.

Tendo em vista que, na escrita do TCC, a conclusão deve estar intimamente ligada à introdução, notamos que 27 trabalhos não respondem às questões norteadoras e aos objetivos propostos na introdução. Outros 29 fazem isso. $\mathrm{F}$ mostram as limitações do estudo. No entanto, apenas 14 TCC apresentam sugestões para a pesquisa.

No TCC 50 (Quadro 9), podemos visualizar que seu produtor responde aos objetivos que propõe na introdução:

Quadro 9-Trecho de uma conclusão

TCC50: Respondendo ao primeiro objetivo, constatamos que a escola onde a pesquisa foi realizada, não oferece condições e ambientes para a leitura, visto que em sua estrutura faltam bibliotecas e livros e em sua programação não constam planos e programas de leitura.

Fonte: Arquivo da pesquisa.

No TCC25 (Quadro 10), o produtor expõe as limitações de sua investigação, atitude louvável, pois revela que nem tudo vai acontecer como se pensou e/ou que as pesquisas podem sim possuir limitações. Isso decorre de as variações sociais, econômicas e históricas afetarem o desenvolvimento de uma pesquisa.

Quadro 10 - Trecho de uma conclusão

TCC25: Porém, mesmo com algumas limitações referentes ao terceiro objetivo, foi possível os dois primeiros. Mas que isso, foi possível aprender sobre a cultura em si, culturas da família e da escola. A pesquisa proporcionou entender mais sobre as pessoas, como elas se diferem uma das outras, dependendo do seu contexto social, cultural e familiar.

Fonte: Arquivo da pesquisa. 
Apresentar, na conclusão de um TCC, sugestões para a pesquisa é uma maneira de traçar perspectivas futuras, que podem envolver uma proposta de solução ou apenas uma projeção do que deverá acontecer, considerando determinados contextos. Podemos ver isso no Quadro 11:

\section{Quadro 11 - Trecho de uma conclusão}

TCC20: Diante de tal contexto, esclarecemos a relevância de uma formação que leve em consideração as especificidades infantis, a fim de que a criança seja entendida em toda sua complexidade, pois só assim enriqueceria a prática pedagógica. Essa é uma sugestão que a pesquisa deixa para o campo da formação de professores da educação infantil.

Fonte: Arquivo da pesquisa.

Em ambos os casos (propor uma solução ou sugerir apenas uma projeção), o autor precisa basear-se nos conteúdos analisados no TCC, em que os dados empíricos foram discutidos à luz da teoria. Não é possível apresentar propostas para problemas que não foram discutidos ou perspectiva futura que não esteja embasada em dados presentes (MORETTO, 2014).

A partir das recomendações acima e do que avaliamos sobre a escrita da conclusão, devemos evitar três fatores. Um deles é a inserção de dados obtidos em outros trabalhos. Outro é a discussão de aspectos que não são provenientes dos resultados. Por fim, há a extrapolação equivocada dos resultados da investigação.

Durante a escrita de qualquer TCC, seu produtor faz uso de citações diretas ou indiretas, suspostamente, porque elas buscam garantir autenticidade do texto, sua cientificidade. Para Moretto (2016, p.114), o uso de citações cria "no leitor a imagem de que ali se predomina um discurso que contém veracidade. O TCC, nesse sentido, é um texto altamente polifônico", dirigido a um público específico, que tenha algum conhecimento das citações usadas. Isso deixa claro que o texto tem um destinatário e que este poderá avaliá-lo.

Dos 56 TCC analisados, 49 usam citações diretas como dispositivo para fortalecimento de seu texto. Podemos supor que isso aconteça devido à ausência de domínio da paráfrase e da análise dos textos lidos, pois não se reescreve, analiticamente, aquilo que não foi compreendido. Há também o uso excessivo de citações de citação, o chamado apud. Um exemplo disso está no Quadro 12. 
Quadro 12 - Trecho de um TCC com citações

TCC13: Mesmo no momento em que as mulheres começavam a exercer atividades fora do lar, estas eram rigidamente contratadas e dirigidas por homens. Os salários eram inferiores, as jornadas de trabalho eram maiores que a dos homens, por isso as reivindicações nas fábricas eram constantes, a exploração de mulheres e crianças demonstrava quem estava no poder. Everaldo Dias (apud BAUER, 2001, p.132) diz que nas fábricas no começo do século XX,

o proletariado fabril, em grande parte era feminino constituído de mocinhas, era o preferido para a industrial têxtil [...]. Os homens eram só os contramestres, tecelões especializados [...] $\mathrm{Na}$ indústria metalúrgica ou mecânica, o número de menores também era predominante, sendo que aqui o sexo aceito era o masculino.

É notável que a divisão sexual do trabalho sempre foi uma fonte de discriminação e desigualdade, onde se perpetuava a situação de inferioridade e subordinação feminina nos espaços de trabalho.

Fonte: Arquivo da pesquisa.

Como podemos ver acima, ainda que não seja usada de forma única em todos os trabalhos, a citação direta aparece sempre associada a outra forma de intertextualidade, o apud, e, particularmente, a comentários avaliativos, que são utilizados como suporte para manter o posicionamento do produtor do TCC. Diversos autores utilizam textos já existentes e reconhecidos, chamados de textos-fonte, para servir de base a suas novas criações. Os estudantes que produzem seus TCC fazem uso deste mecanismo: intertextualidade. Contudo, a dúvida que fica é: eles sabem que a intertextualidade é a relação que se estabelece entre dois textos quando um texto já criado exerce influência na criação de um novo, podendo contribuir para o enriquecimento de um determinado tema? Talvez essa questão fique para novas investigações, mas suspeitamos que poucos alunos saibam dessa característica, pois grande parte dos trabalhos analisados usa a intertextualidade de maneira descuidada.

Reiteramos que as citações buscam garantir uma veracidade predominante no discurso proposto, tornando o TCC um texto polifônico (MORETTO, 2014, 2016). Assim, é feito o uso de diferentes formas de potencializar e assumir o que foi dito no texto escrito como forma de autoafirmação. Por isso,

a citação, recurso tão presente em textos desse gênero, torna-se um elemento privilegiado de acomodação, um lugar de reconhecimento, uma marca de leitura conforme expõe Compagnon (2007). Ela integra aquilo que o enunciador quer dizer a um conjunto ou rede de textos legitimados nessa área de conhecimento. Faz valer o seu discurso à medida que ali autores legitimados dizem. Cria-se, conforme aponta Maingueneau (2011), a autenticidade, 
indicando que as palavras relatadas são as que, de fato, devem ser proferidas (MORETTO, 2016, p.114).

As afirmações que Moretto (2016) faz acima fortalecem a ideia de que os enunciados teóricos de cada TCC revelam recursos linguísticos para se posicionar de acordo com a representação que possuem do contexto de produção de seus gêneros escritos. Nessa perspectiva, os enunciados geram efeitos de sentido que só podem ser analisados no contexto de enunciação e estão relacionados a outros enunciados anteriores e àqueles que ainda estão por vir (BAKTHIN, 2010).

Podemos notar essa ideia no excerto do TCC 9 (Quadro 13), em que a discussão da temática sexualidade é desenvolvida a partir da referência a um autor. O produtor do texto, o enunciador, posiciona-se em relação ao que é dito pelo enunciado do autor referência, firmandose nele por muitas páginas.

Quadro 13 - Trecho do TCC

TCC9: Iniciaremos a análise a partir de 1930, uma vez que na época do Brasil Colônia não havia preocupações emergenciais com a sexualidade, principalmente das mulheres, haja vista que a sexualidade resumia-se apenas no ato sexual, fenômeno muito bem descrito por Del Priore (2011, p.45).

[...] os maridos deviam se mostrar dominadores, voluntariosos no exercício da vontade patriarcal, insensíveis e egoístas. As mulheres por sua vez, se apresentavam como fiéis submissas e recolhidas. Sua tarefa mais importante era a procriação.

Foi a partir da década de 1930 que os médicos começaram a pensar numa orientação sexual para os jovens, que tinham muitas dúvidas e que não eram sanadas por conta do grande sigilo com que o sexo era tratado. De acordo com a educação sexual da época, os principais objetivos eram:

[que os homens] não contraíssem moléstias venéreas e [que as mulheres] aprendessem mais sobre a maternidade [...] $O$ ensino deve orientar-se de modo que aos impúberes se ministrem noções de História Natural, Fisiologia e Higiene, e aos púberes se alarguem gradativamente os conhecimentos de modo a evitar-Ihes as surpresas desta perigosa fase da vida (DEL PRIORE, 2011, p.126-127).

Notamos que a orientação sexual que existia na época acima tinha caráter apenas higienista e naturalista, somando isto ao fato de que apenas os homens podiam ter acesso a informações sobre sexo, acentuou mais ainda a afirmação de que mulheres eram inferiores, e as tornavam mulheres sem voz e sem vez, sua única função era procriar. Tal situação perdurou firmemente até o final do século XIX, quando se iniciou um movimento de mulheres que lutaram pela igualdade entre mulheres e homens; o movimento marcou a luta das mulheres pelos seus direitos e reconhecimento perante a sociedade como seres capazes de produzir e fazer parte do mercado, ele ficou conhecido como Movimento Feminista, teve três grandes fases, ou ondas.

Fonte: Arquivo da pesquisa. 
Para analisarmos um enunciado, é preciso observá-lo a partir de sua relação dialógica, ou seja, é necessário constatar como cada enunciado é um elo na corrente de outros enunciados (MORETTO, 2014, 2016). Essa corrente só pode ser vista em sua atuação e materialização linguística, a exemplo dos textos verbais, orais ou escritos. Sendo assim, podemos compreender o enunciado e o texto como um só fenômeno concreto. Então, o texto do TCC é uma ressonância de vozes, e isso é um dos muitos cuidados que seu produtor carece de saber.

Voltemos agora nosso olhar para as referências. De acordo com a norma ABNT/NBR 6023, de 2018, elas são "um conjunto padronizado de elementos descritivos, retirados de um documento, que permite sua identificação individual." (ABNT, 2018). A referência é constituída de elementos essenciais e, quando necessário, contém elementos complementares. Elas podem ser ordenadas conforme o sistema utilizado para a citação no texto, seguindo uma organização alfabética, cronológica e sistemática (por assunto). Nos trabalhos técnicos e científicos, as ordenações mais utilizadas são: numérica (ordem de citação no texto) e alfabética (sistema autor-data). Todas as obras citadas devem ser listadas no final do trabalho.

Analisando os 56 TCC, notamos que as referências são ordenadas alfabeticamente. Há também, em todos os trabalhos, a presença de pelo menos uma referência feita de maneira equivocada: escrita dupla do nome do autor; falta de identificação da cidade onde a obra foi feita ou da editora; ano da obra errado; vírgula no lugar de ponto; em artigos de periódicos, destaque dado ao título do artigo, e não ao nome do periódico; em documentos e/ou site da internet, desconsideração da norma. Os estudantes poderiam ter sanado essas dificuldades durante o curso, em suas muitas escritas acadêmicas, ou solicitado ajuda de um especialista na revisão do TCC.

Avaliando o letramento acadêmico demonstrado nos TCC de 2013 a 2016 dos estudantes de Pedagogia de uma universidade maranhense, identificamos a cultura particular dos acadêmicos na maneira de construir seus discursos, na tentativa de aproximar-se do discurso do outro. Essa habilidade, em nosso entendimento, deveria se desenvolver durante o curso, pois é na universidade que se adquirem modos de falar, escrever, pensar e interagir em práticas de letramento que os caracterizam como membros de uma comunidade específica. E a produção do TCC vai além do contexto físico e imediato, da conjuntura da linguagem e do âmbito sóciohistórico. Os estudantes e a comunidade acadêmica devem se preocupar mais com a produção dos TCC, pois 
os textos produzidos têm a finalidade não apenas de levar esses alunos a concluírem o curso de graduação, mas contribuir com a literatura científica vigente e com as instâncias sociais já que alguns deles são submetidos à publicação em periódicos científicos e/ou publicados no site da instituição para divulgação. Seus destinatários assumem, além de professores, o papel social de pesquisadores e colaboradores do mundo científico (MORETTO, 2016, p.111).

O letramento acadêmico pautado nos TCC analisados é construído nas relações que se estabelecem entre os gêneros discursivos diante do tema a ser abordado e da forma composicional. Elas obedecem ao prescrito na ABNT e ao estilo ou forma individual de enunciar.

O envolvimento contínuo e crescente do aluno com a leitura e produção dos gêneros mais valorizados na universidade, bem como sua inserção nas práticas de leitura e escrita que o cercam, será um fator decisivo para a construção de sua identidade, autonomia e reflexão acerca dos conteúdos aprendidos ao longo da vida acadêmica. Isso pode proporcionar a ele melhores condições para decidir o que escrever e para seguir as regras da ABNT na escrita do TCC.

\section{Considerações finais}

Tendo os desafios da produção do TCC como temática central deste artigo, podemos dizer que sua produção vai além do contexto físico e imediato, da conjuntura da linguagem e do âmbito sócio-histórico. Os estudantes e a comunidade acadêmica devem se preocupar mais com seu contexto de produção, pois seus produtores assumem, além da função de docentes, o papel social de investigadores e colaboradores do mundo científico.

Por isso, ao analisarmos os desafios do letramento acadêmico revelados nos TCC dos alunos do curso de Pedagogia do período de 2013 a 2017, podemos dizer que eles residem no uso das relações dialógicas, na sustentação da argumentação fundamentada nos enunciados teóricos. Os discentes necessitam apropriar-se do letramento acadêmico para inserirem-se no espaço universitário, com a produção de resumos acadêmicos, resenhas, fichamentos, mapas mentais e/ou conceituais e também divulgando suas produções.

Avaliamos que os TCC foram estruturados nas normas da ABNT. Contudo, algumas dificuldades na escrita do título (composição em um contexto determinístico, repetição do fazer científico usando verbos em sua escrita, deixando-o prolixo, assim aconselha-se que seja 
constituído por frase nominais), no emprego de citações (ausência de domínio da paráfrase e da análise dos textos lidos, o uso excessivo de citações de citação, o chamado apud, e uso da intertextualidade de maneira descuidada) e na produção do resumo (escrito na primeira pessoa do singular ou plural deve ser substituída pela terceira pessoa do pretérito perfeito, expondo um momento anterior à enunciação real e descrevendo como a investigação aconteceu, garantindo sua objetividade, sua imparcialidade e sua cientificidade, como sugere a norma ABNT/NBR 6028, de 2003) são destaques que revelam lacunas na aprendizagem do letramento acadêmico e necessitam de reparos.

Identificamos a cultura particular do estudante na maneira de construir seus enunciados, na tentativa de aproximar-se do discurso do outro. Essa habilidade, em nosso entendimento, deveria acontecer durante o curso, pois é na universidade que se adquirem modos de falar, escrever, pensar e interagir em práticas de letramento que os caracterizam como membros de uma comunidade específica.

Ao finalizarmos a escrita deste artigo, precisamos dizer que não temos a pretensão de apresentar uma discussão fechada sobre a escrita do TCC, tampouco sobre o letramento acadêmico. Nossa contribuição gira em torno do que acreditamos como importante no espaço universitário: ler com competência e escrever com autonomia no ambiente acadêmico são habilidades fundamentais para a construção de um pensamento crítico e reflexivo. Para isso, fazse necessário apropriar-se do gênero do discurso acadêmico.

\section{Referências}

ASSOCIAÇÃO BRASILEIRA DE NORMAS TÉCNICAS - ABNT. NBR 6023: Informação e documentação: Referências: Elaboração. Rio de Janeiro, 2018. Disponível em: https://www.ufpe.br/documents/40070/1837975/ABNT+NBR+6023+2018+\%281\%29.pdf/3021 f721-5be8-4e6d-951b-fa354dc490ed. Acesso em: 26 jun.2020.

ASSOCIAÇÃO BRASILEIRA DE NORMAS TÉCNICAS - ABNT. NBR 6028: Informação e documentação: Resumo: Apresentação. Rio de Janeiro, 2003.

BAKHTIN, M. Os gêneros do discurso. In: BAKHTIN, M. Estética da criação verbal. 4. ed. São Paulo: Martins Fontes, 2010. p.261-306. 
FLICK, U. Introdução à pesquisa qualitativa. Trad. Joice Elias Costa. 3. ed. Porto Alegre: Artmed, 2009.

GEE, J. P. Reading as situated language: a sociocognitive perspective. Journal of Adolescent \& Adult literacy, Newark Delaware, v.44, n.8, p.714-725, maio 2001. Disponível em:

http://www.jamespaulgee.com/pdfs/Reading\%20as\%20Situated\%20Language.pdf Acesso em: 10 fev. 2020.

GEE, J. P. The new literacy studies: from 'socially situated' to the work of the social. In: BARTON, D.; HAMILTON, M.; IVANIC, R. (orgs.). Situated literacies: reading and writing in context. London: Routledge, 2000. p. 180-196.

GEE, J. P. Social linguistics and literacies: ideology in discourses. 2. ed. London: The Farmer Press, 1999.

HELDER, R. F. Como fazer análise documental. Porto: Universidade de Algarve, 2006.

HENRY-SILVA, G. G.; SOEIRO, M. I. P.; CAMARGO, A. F. M. Caminhos para a publicação científica. Boletim da Sociedade Brasileira de Limnologia, São Paulo, v.37, p.1-10, 2009. Disponível em: https://www.ablimno.org.br/boletins/pdf/bol_37(1-4).pdf. Acesso em: 10 jan. 2020.

IMBELLONI, L. E. Títulos de trabalhos científicos: obrigado pela informação contida em seu título. Rev.Bras. Anestesiol, Campinas, v.62, n.2, p.140, mar./abr. 2012. Disponível em: https://www.scielo.br/pdf/rba/v62n2/v62n2a01.pdf. Acesso em: 23 nov. 2019.

KLEIMAN, A. B. Introdução: modelos de letramento e as práticas de alfabetização na escola. In: KLEIMAN, A. B. (org.). Os significados do letramento: uma nova perspectiva sobre a prática social da escrita. Campinas: Mercado das Letras, 2008, p. 15-61.

LEA, M. R.; STREET, B. V.O modelo de "letramentos acadêmicos": teoria e aplicações. Trad. Fabiana Komesu e Adriana Fischer. Filol. Linguíst. Port., São Paulo, v.16, n.2, p.477-493, jul./dez. 2014. Disponível em: http://www.revistas.usp.br/flp/article/view/79407/95916. Acesso em: 10 maio 2019.

LEA, M. R.; STREET, B. V. The academic literacies model: theory and applications. Theory into Practice, London, v.4, n.45, p.368-377, jun. 2006.

MARQUESIN, D. F. B.; BENEVIDES, C. R.; BAPTISTA, D. C. Leitura e escrita no ensino superior. Revista de Educação, Londrina, v.14, n.17, p.9-28, 2011. Disponível em: https://revista.pgsskroton.com/index.php/educ/article/view/1801. Acesso em: 26 maio 2020.

MARTINS, G. A. Manual para elaboração de monografias e dissertações. 2. ed. São Paulo: Atlas, 2000. 
MENDES, R. S. A importância da adequada estruturação de resumo e resenha. Revista Espaço Acadêmico, Maringá, v.10, n.114, p.135-140, nov.2010. Disponível em: http://www.periodicos.uem.br/ojs/index.php/EspacoAcademico/article/view/10753. Acesso em: 25 nov. 2019.

MORETTO, M. Os recursos linguísticos utilizados por graduandos na construção de trabalhos de conclusão de curso. Revista Intercâmbio, São Paulo, v.XXXII, p.102-118, 2016.

MORETTO, M. Um modelo didático do gênero trabalho de conclusão de curso e uma perspectiva de trabalho em sala de aula. 2014. 212f. Tese (Doutorado em Educação) Programa de Pós-Graduação Stricto Sensu em Educação, Universidade São Francisco, Itatiba, 2014. Disponível em: https://www.usf.edu.br/galeria/getlmage/427/12628965019294038.pdf. Acesso em: 20 fev. 2019.

MORTATTI, M. R. L. Educação e letramento. São Paulo: UNESP, 2004.

NAJMANOVICH, D. O sujeito encarnado: questões para pesquisa no/do cotidiano. Rio de Janeiro: DP\&A, 2001.

RIOLFI, C. R.; ANDRADE, E. Ensinar a escrever texto acadêmico: as múltiplas funções do orientador. Trabalhos em Linguística Aplicada, Campinas, v.48, n.1, p.99-118, jun.2009. Disponível em: https://periodicos.sbu.unicamp.br/ojs/index.php/tla/article/view/8645258. Acesso em: 2 mar. 2020.

SEVERINO, A. J. Metodologia do trabalho científico. São Paulo: Cortez, 1996.

SILVA, E. M.; ARAÚJO, D. L. Letramento: um fenômeno plural. RBLA, Belo Horizonte, v.12, n.4, p.681-698, 2012. Disponível em: https://www.scielo.br/pdf/rbla/v12n4/aop0812.pdf. Acesso em: 30 ago. 2019.

STREET, B. Academic literacies approaches to genre? RBLA, Belo Horizonte, v.10, n.2, p.347361, 2010. Disponível em: https://www.scielo.br/pdf/rbla/v10n2/04.pdf. Acesso em: 20 abr. 2020.

Recebido em março 2021.

Aprovado em maio 2021. 